\section{Rapid Excision Apparatus for Plants (REAPer): Design, Implementation, and Functionality}

\author{
Gerard W. Wall ${ }^{1}$
}

U.S. Department of Agriculture, Agricultural Research Service, U.S. Water Conservation Laboratory, 4331 E. Broadway Road, Phoenix, AZ 85040

\section{Guy McDonnell ${ }^{2}$ \\ Department of Plant Biology, P.O. Box 871601, Arizona State University, Tempe, AZ 85287}

Additional index words. cavitation, emboli, stomatal conductance, transpiration rate, xylem conductance

\begin{abstract}
Net primary productivity of a botanical is often determined by monitoring gas exchange rates (i.e., $\mathrm{CO}_{2}, \mathrm{H}_{2} \mathrm{O}$ ) in a controlled-environment cuvette. Because atmospheric conditions (i.e., incident photon flux density, air temperature, and water vapor pressure) change within a day, whereas edaphic (i.e., soil-water content and nutrient availability) conditions change across days, experimental results obtained between treatment variants can often be confounded within the sample interval. Consequently, in order to obtain a "snapshot" of the $\mathrm{CO}_{2}$ and $\mathrm{H}_{2} \mathrm{O}$ flux of a botanical across treatment variants, all in situ measurements must be made within a discrete interval. One approach would be to use multiple cuvettes to measure $\mathrm{CO}_{2}$ and $\mathrm{H}_{2} \mathrm{O}$ flux across all treatment variants simultaneously. But, this would be expensive in both equipment and personnel cost. A more economical approach would be to rapidly excise a botanical from each treatment variant within a discrete interval and store them under exacting steady-state laboratory conditions for in vivo rather than in situ studies. However, this too can be problematic, because in order to excise a botanical a standard operating procedure (SOP) is required. Hence, a need exists for a Rapid Excision Apparatus for Plants (REAPer). Following the SOP of the REAPer enables personnel to excise a botanical across all treatment variants within a discrete interval, while maintaining xylem conductance, minimizing mechanical damage, and providing a uniform sample for in vivo rather then in situ studies. This work describes the design, implementation, and functionality of the REAPer, its application in basic research and development, and its potential applications in the commercial floral and horticultural industries.
\end{abstract}

Monitoring the physiological response of plants from dawn to dusk as atmospheric conditions change within a day, and across growing season as edaphic conditions change, has enabled scientists to characterize and quantify net primary productivity in plants. One such

Received for publication 16 Nov. 2001. Accepted for publication $22 \mathrm{Aug}$. 2002. Support for this research was provided by a grant from the Howard Hughes Medical Institute through the Undergraduate Biological Sciences Education Program, Dept. of Biology, Arizona State Univ., Tempe, Ariz. Operationa support was also contributed by the Agricultural Research Service, U.S. Dept. of Agriculture, U.S Water Conservation Laboratory, Phoenix, Ariz., and the NSF/DOE/NASA/USDA Interagency program on Terrestrial Ecology and Global Change (TECO II) (NSF-95-27 proposal no. IBN-9652614) (Gerard W. Wall, PI). Special thanks to Mr. Jose Olivieri for design input and fabrication of the REAPer device and Ms. Laura Olivieri for assistance with figures. Mention of a trademark or proprietary product does not imply an endorsement or recommendation by the authors or their institutions over products not mentioned.

${ }^{1}$ Research Plant Physiologist; to whom reprint requests should be addressed. Phone: (602) $437-$ 1702, ext. 279; fax: (602) 437-5291; e-mail: gwall@uswcl.ars.ag.gov

${ }^{2}$ Hughes Fellow. physiological response of importance is that of gas exchange (i.e., $\mathrm{CO}_{2}, \mathrm{H}_{2} \mathrm{O}$ ) (Wall et al., 2000, 2001). Quantification of the flux of $\mathrm{CO}_{2}$ and an indication of carbon uptake for growth and maintenance processes per unit water used for a given combination of predetermined treatment set points.

Gas exchange processes, such as net assimilation [A: $\mu \mathrm{mol}\left(\mathrm{CO}_{2}\right) \mathrm{m}^{-2} \cdot \mathrm{s}^{-1}$ ] and transpiration [T: mmol $\left(\mathrm{H}_{2} \mathrm{O}\right) \mathrm{m}^{-2} \cdot \mathrm{s}^{-1}$ ] rates, and stomatal conductance $\left[\mathrm{g}_{\mathrm{s}}: \mathrm{mol}\left(\mathrm{H}_{2} \mathrm{O}\right) \mathrm{m}^{-2} \cdot \mathrm{s}^{-1}\right]$, can be monitored both in the wild and under exacting steady-state laboratory conditions. Gas exchange properties are determined by placing a plant part, usually a leaf (hereafter referred to as a botanical), in a controlled-environment cuvette in tandem with an infrared gas analyzer (Long and Hällgren, 1993). This methodology is useful because the cuvette can control atmospheric conditions, such as photosynthetic photon flux density, air temperature, water vapor pressure, and carbon dioxide and oxygen concentrations at predetermined set points, thereby eliminating them as confounding factors. One caveat, however, is that $\mathrm{CO}_{2}$ and $\mathrm{H}_{2} \mathrm{O}$ exchange rates can be confounded with the artificial conditions imposed on the botanical by the cuvette itself. Nevertheless, $\mathrm{H}_{2} \mathrm{O}$ in plants is important because it provides the benefit of obtaining information about $\mathrm{CO}_{2}$ and $\mathrm{H}_{2} \mathrm{O}$ flux under controlled-environment conditions overwhelms any minor artifacts associated with the use of a cuvette.

Because physiological and biochemical processes within the botanical can acclimate to environmental conditions throughout the daylit period as the environment changes, in situ measurement of $\mathrm{CO}_{2}$ and $\mathrm{H}_{2} \mathrm{O}$ flux of a botanical can be problematic. Experimental results from one treatment variant measured at one time of day can be confounded with another taken later in the sample interval simply because of a change in environmental conditions. Consequently, it is virtually impossible to compare results between different treatments measured during different times of the day. Valid treatment comparisons can only be made if relatively discrete intervals of time elapse while measurements are made across all treatment variants. However, the measurements themselves take time. This constitutes a logistical dilemma because all experimental units within the experimental design must be measured before significant changes in environmental conditions occur. Therefore, a balance must be established between the sample interval and any change in atmospheric factors that occur over the measurement interval. Because edaphic factors such as soil-water content and nutrient availability vary between days more so than within a day, they change on a much coarser time scale. During an in situ study, therefore, results obtained at discrete intervals of the daylit period on different days of the year can be used to determine the interaction between treatment variants and changes in edaphic factors and ontogeny of the subject botanical.

One method to minimize the confounding effect of changes in atmospheric and edaphic factors is the use of multiple cuvettes and infrared gas analyzers, so that all treatments can be measured simultaneously. But, this is expensive in both equipment and personnel costs. An alternative approach would be to excise a botanical from each experimental unit in a relatively short interval, so that reliable estimates of the physiological response of the botanical can be obtained during a discrete interval. The botanical can then be stored under exacting steady-state laboratory conditions until processed, thereby negating the effect of any change in atmospheric factors on physiological response. However, this approach can also be problematic. Because the water column in xylem elements are under tension (negative potential), upon excision the botanical is exposed to atmospheric pressure, resulting in the formation of an emboli in the xylem water column. Furthermore, wound responses can affect xylem conductance, and sealing of the xylem can occur due to exudates oozing out of the phloem. Lastly, upon excision mechanical damage to the xylem can also occur. Any one or a combination of these effects will disrupt water flow in the xylem, thereby disrupting xylem conductivity (McCully, 1999; Savage et al., 1984).

In many studies the procedure used to excise a botanical is not well defined. Van Wijk 
and Van Hasselt (1993) and De la Torres et al. (1991) did not discuss the excision process used in their study. Likewise, in a study to determine the effect of elevated $\mathrm{CO}_{2}$ on rooting and subsequent growth in ornamental species, Davis and Potter (1983) simply stated that cuttings were obtained. Whenever a method for excising a botanical was reported, it usually was described as one of the following procedures: 1) the botanical is excised and the cut end is immersed in solution (Carter et al., 1995; Housley and Pollock, 1985; Jia et al., 1996; Pena-Cortez et al., 1992; Zeyen et al., 1995); 2) an expansion of the first method is described, which includes performing a second cut after immersing the botanical in water (Barrat and Clark, 1992; Krapp et al., 1991; Li et al., 1996) - a second cut is performed while the botanical is submerged in water to remove the section of the xylem water column containing the emboli formed from the first cut, and to prevent the formation of another emboli further up the water column; and, 3) excises the botanical while it is submerged in solution (Bakrim et al., 1992; Delhon et al., 1996; Jia et al., 1996; Sugiharto et al., 1992). In the second and third procedure, after the botanical is excised it is usually transferred to a sample cuvette while submerged in water. This ensures that an emboli will not form when the botanical is removed from solution and exposed to atmospheric pressure. The primary factors that affect the integrity of a botanical following excision include: 1) angle of the excision-Krapp et al. (1991) used an oblique angle; 2 ) implement used to make the excision-Sugiharto et al. (1992) reported using a razor blade; 3 ) range in motion used to perform the excision; and 4) the stability of the surface supporting the plant material being excised. Furthermore, these confounding factors are most likely species specific and vary across different function types.

To establish a new methodology for excision of a botanical, we developed the Rapid Excision Apparatus for Plants (REAPer). During its conceptual development the following functional characteristics of the REAPer's design were considered: it should 1) standardize the excision of a botanical; 2) prevent the formation of an emboli in xylem elements; 3) minimize clogging of xylem from either phloem exudates or wound response; and 4) minimize mechanical damage to the excised botanical. Reported herein is a simple description of the design, implementation, and functionality of the REAPer.

\section{Materials and Methods}

Design of REAPer. An overall view of the REAPer is illustrated in Figure 1. A detailed materials and parts list is given in Table 1 . Individual components of the REAPer (Fig. 2) are as follows: (a) two top side-walls fabricated from 13-mm Plexiglas measuring $41 \mathrm{~mm} \times 28 \mathrm{~mm}$; (b) three plates fabricated from 13-mm Plexiglas measuring $76 \mathrm{~mm} \times$ $64 \mathrm{~mm}$ - one plate contains a striker assembly channel; (c) two top side-walls fabricated from 13 -mm Plexiglas measuring $76 \mathrm{~mm} \times 28 \mathrm{~mm}$;
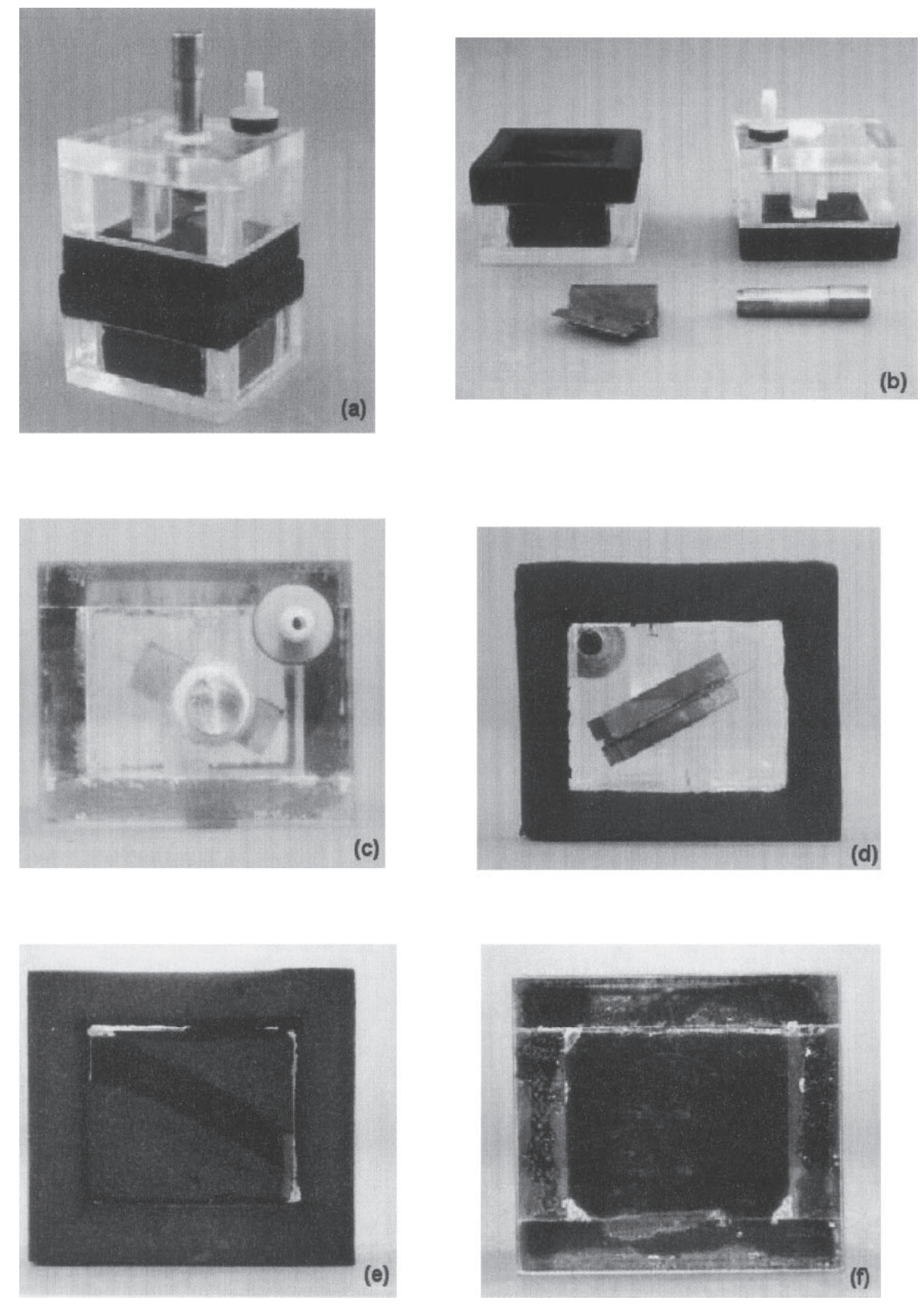

Fig. 1. Overall view of the Rapid Excision Apparatus for Plants (REAPer) after assembly (a). An exploded view of the major components of the REAPer illustrating bottom (upper left) and top (upper right) components of the reservoir, striker assemble (lower left), and plunger (lower right) (b). Top view of the upper reservoir component, plunger, plunger seal, and one-way check valve (c). An inside view of the upper reservoirs component showing the striker assembly (i.e., striker body, striker clamp, standard razor blade, and set screw), striker guides, and one-way check valve (d). An inside view of the bottom reservoir component illustrating the lower half of the closed-cell rubber gasket and striker channel (e). Top view of the lower reservoir component showing the lower half of the closed-cell rubber gasket (f).

(d) two closed-cell rubber gaskets fabricated with a thickness of $19 \mathrm{~mm}$ measuring $76 \mathrm{~mm}$ $\times 64 \mathrm{~mm}$ with a wall thickness of $10 \mathrm{~mm}$; (e) plunger fabricated from brass; (f) two striker guides fabricated from 13-mm Plexiglas with the base measuring $25 \mathrm{~mm} \times 13 \mathrm{~mm}$ at an acute angle of $30^{\circ}$; striker assembly fabricated from brass containing (g) standard razor blade, (h) striker body, (i) striker clamp and set screw (not shown); (j) plunger seal fabricated from nylon; (k) a one-way flow check valve (Model BK 7301347, Balankamp Inc., Indianapolis); mariott bottle reservoir and rubber connecting tube (not shown) to supply water to the oneway check valve.

All Plexiglas components were assembled using a commercially available adhesive (Weld-ON 16, IPS Corp., Gardenia, Calif.). Assembly was as follows: the top side-walls (a) and (b) were fixed to each other and one of the plates (c); the striker guides (f) were fixed to the underside of the top plate (c); and the side-walls (b) were placed with the leading edges 41 and $43 \mathrm{~mm}$ from the side walls (a), respectively. One-half of the closed-cell rubber gasket (d) was fixed to the bottom of 
the top assembly completing the top of the reservoir. To construct the bottom half of the reservoir, the two remaining plates (b) were fixed together - the upper plate containing the striker assembly channel was fixed to the base plate. To complete the assembly of the bottom reservoir, the remaining half of the closed-cell rubber gasket (d) was fixed to the upper plate containing the striker assembly channel. Both the plunger seal $(\mathrm{j})$ and the check valve $(\mathrm{k})$ were press fit into the top plate (b). The plunger (e) was inserted through the plunger seal and press fit into the striker body (h). The striker clamp (i), containing a standard razor blade (g), was then attached to the striker body with a brass set screw. Lastly, a mariott bottle with a rubber connecting tube was attached to the one-way check valve (not shown).

The plunger and components of the striker assembly are all made of brass to ensure enough critical mass for a precise excision and to maintain sanitary conditions. The range of motion of the plunger and striker assembly $(36 \mathrm{~mm})$ and the exposed portion of the razor blade $(0.48$ $\mathrm{mm}$ ), along with the acute angle of the razor blade $\left(30^{\circ}\right)$, provides for a maximum target botanical diameter of $9.5 \mathrm{~mm}$. A large range of motion ensured that a large number of species across multiple functional types can be sampled, thereby insuring the potential widescale application of the REAPer. The angles of the striker assembly were $60^{\circ}$ and $30^{\circ}$ with respect to the vertical and the horizontal axes, respectively. This configuration ensured a maximum shear during the excision process, thereby maximizing the exposed surface area for maximum xylem conductance after the excision. The closed cell rubber gasket is capable of compressing to $50 \%$ of its original thickness, providing a maximum compression of $19 \mathrm{~mm}$. Thus a wide range in botanical diameters can be excised, while maintaining a tight water seal around the botanical protruding from outside of the reservoir.

Standard operating procedure (SOP). To operate the REAPer, the upper and lower halves of the reservoir are placed around the desired botanical and clamped shut so that the closed-cell rubber gaskets on each half of the reservoir create a watertight seal. Next, the mariott bottle is raised above the reservoir and inverted, enabling the flow of water through the connecting tube through the one-way check valve into the reservoir of the REAPer. Once the reservoir is full, the mariott bottle is set aside, or the connecting tube is disconnected at the one-way check value. Next, the plunger is pressed over the entire range of motion of the striker assembly, through the striker guides to the base plate. After the botanical has been excised, the REAPer is then submerged under water. Lastly, while the in situ botanical excised by the REAPer is submerged, it should be transferred to the sample cuvette containing a similar solution and stored under exacting steady-state laboratory conditions for in vivo analysis.

Implementation. REAPer was tested on an irrigated sour orange tree (Citrus aurantium L.) grown in Phoenix, Ariz. Paired samples were collected by first excising a vegetative

Table 1. Manufacturer's parts and raw material used in the fabrication of Rapid Excision Apparatus for Plants (REAPer).

\begin{tabular}{llll}
\hline Part no. & \multicolumn{1}{c}{ Material } & Catalogue no. & \multicolumn{1}{c}{ Manufacturer } \\
\hline A & Brass & BK.7301347 & Balkamp, Inc., Indianapolis, Ind. \\
& & & Capitol Metals, Phoenix, Ariz. \\
& Plexiglas & & Century Plastics, Phoenix, Ariz. \\
& Closed-cell rubber gasket & & Central Plastic and Rubber Co., Phoenix, Ariz. \\
\hline
\end{tabular}

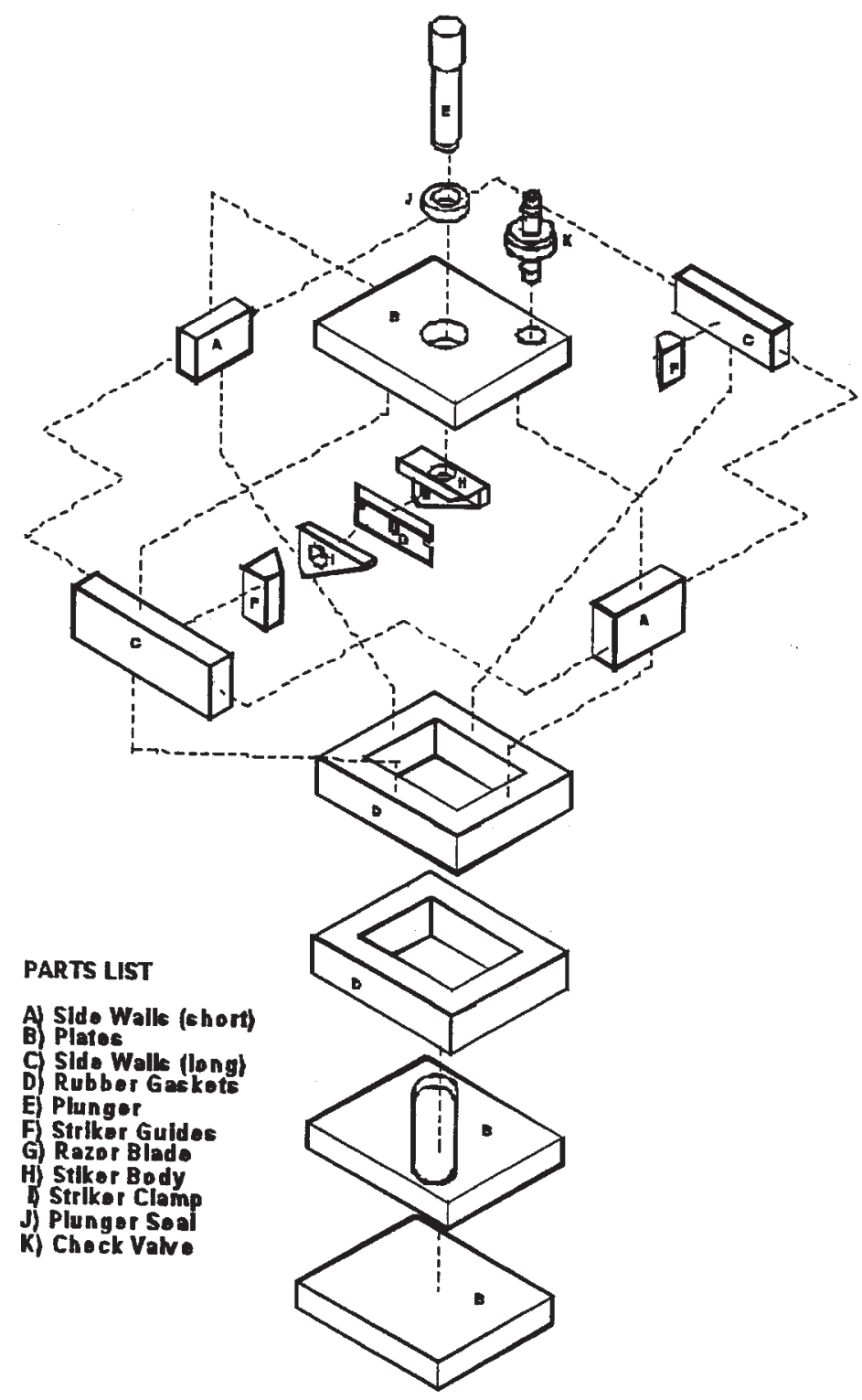

Fig. 2. Schematic illustrating an exploded view of the Rapid Excision Apparatus for Plants (REAPer) and list of major components.

branch of a sour orange tree using the SOP for the REAPer, whereas a control sour orange branch was excised manually $\approx 13 \mathrm{~mm}$ away from that excised with the REAPer. The manual excision was performed by placing the target stem against a small Plexiglas cutting board $(130 \mathrm{~mm} \times 160 \mathrm{~mm} \times 10 \mathrm{~mm})$ and dragging a standard razor blade across the stem. Excising the samples from the same stem of the orange tree ensured that comparable diameters of similar age cohorts were sampled. Pairs of samples were then placed together under a dissecting microscope (Model Semi SV11, Zeiss, Germany) with a $10 \times$ eyepiece and photographed using a $35 \mathrm{~mm}$ camera (Model 476072-9901, Minolta Co., Osaka, Japan) mounted on the microscope and connected to a sensor/controller(Model MC63,Zeiss). Light was provided by a Schott electronic condenser (Model KL 1500, Zeiss) set at maximum illumination. This process was repeated after staining the excised area with iodine, which increased the resolution of the image.

\section{Results and Discussion}

Because photon flux density, air temperatures, and water vapor pressure change 
throughout the day, completing all diurnal in situ measurements of $\mathrm{CO}_{2}$ and $\mathrm{H}_{2} \mathrm{O}$ gas exchange across predetermined treatment variants before atmospheric conditions change significantly is problematic. In order to minimize any confounding effect of changing environmental conditions, the measurement interval must be kept to a minimum. But, the measurements themselves take time, which constitutes a logistical dilemma. Consequently, a balance must be maintained between the sample interval, where atmospheric conditions can change, and completion of in situ measurements for all experimental units within the experimental design.

Herein, we reported a more efficient approach to collect botanicals across all treatment variants within the experimental design in a discrete time interval and store them under exacting steady-state laboratory conditions for in vivo rather than in situ measurements. One caveat to this approach, however, is that xylem conductance must remain relatively constant throughout the sampling, storage, and measurement periods. The REAPer was designed to excise a botanical without causing an emboli from forming in the xylem that would disrupt the water column, thereby disrupting xylem conductance. This is possible because during the excision the botanical is submerged in water and under slight positive pressure (pressure head dependent on the height of the water in the reservoir above the target botanical). Since the xylem is under negative pressure, any excision causes the water to flow into the xylem until the pressure differential between inside the xylem and the head pressure in the reservoir comes into equilibrium.

Figure 3 a depicts a microscope view (10x) of a 3-mm-diameter branch of a sour orange tree manually excised with a standard razor blade (right) and one of similar diameter excised with the REAPer (left) (a). A solution of iodine was used to enhance the resolution of the excised branches and the magnification was increased to $20 \times$ (Fig. 3b). Because iodine stains carbohydrates, a discrete delineation was observed between the xylem and phloem elements. Thus, any mechanical damage that may have occurred during excision is readily apparent. Note that the stem excised manually (right side) shows evidence of a slight amount of mechanical damage on the upper end of the pith (Fig. 3b). This damage is apparent in both the rivulets into the pith and the slight smearing in the line between the pith and the woody part of the stem. This type of damage is not as readily apparent in the stem excised with the REAPer (left). However, the tendrils projecting from the botanical excised with the REAPer indicate that design improvements are required. For example, a recent improvement is the REAPer design included an anvil at the base of the bottom component of the reservoir to prevent an apparent slight bending of the stem when the plunger is depressed.

Using the SOP of the REAPer to obtain a botanical not only standardized the excision process, but also minimized the formation of emboli in the water column, thereby maintaining xylem conductance. Consequently,
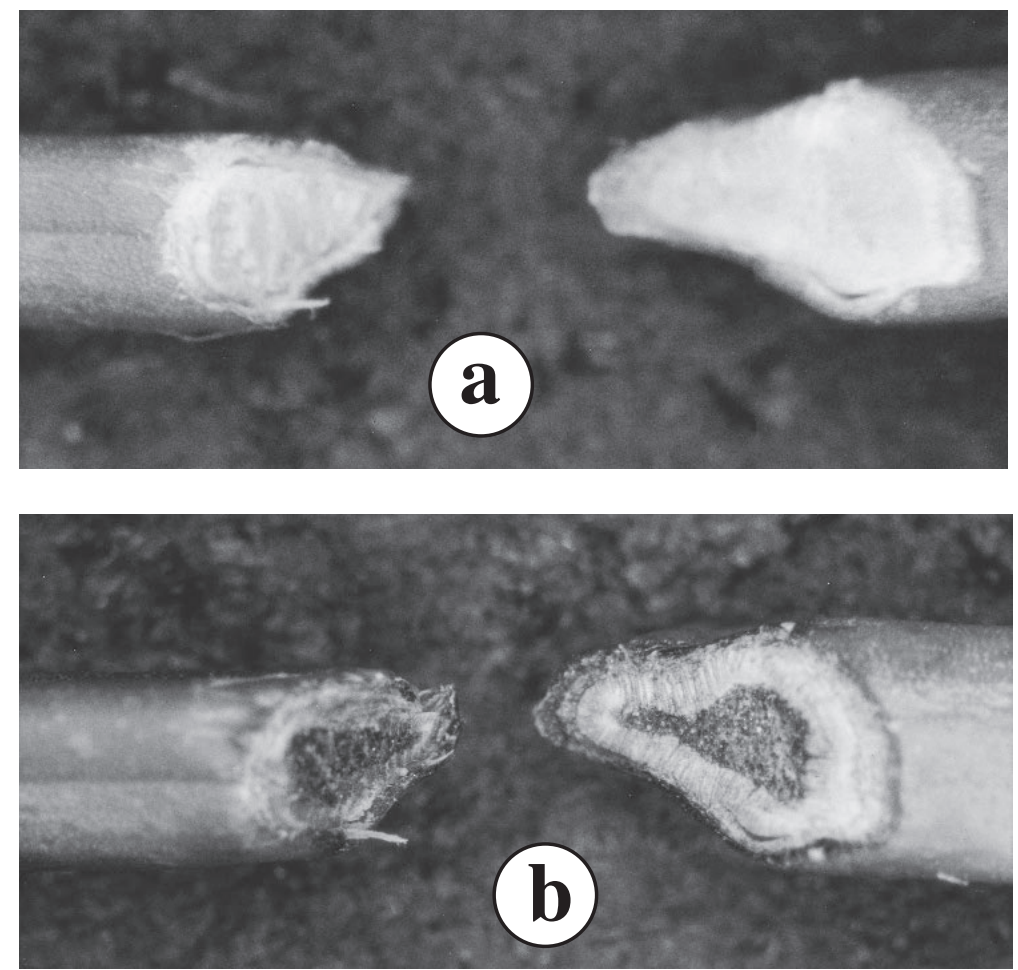

Fig. 3. Pictures taken under a microscope at $10 \times$ magnification of two excised botanicals from an orange tree (Citrus aurantium L.) branch, which are $\approx 3 \mathrm{~mm}$ in diameter. The right stem was excised manually with a standard razor blade, whereas on the left the standard operating procedure of the REAPer was used to excise the botanical (a). The same botanicals were stained with iodine to enhance resolution at $20 \times$ magnification (b).

multiple samples can be obtained in a short enough interval to minimize any confounding effect of changing atmospheric conditions on physiological response. Excised botanicals can then be stored under exacting steady-state laboratory conditions until in vivo gas exchange assays can be performed. One disadvantage of this approach, however, is that when the SOP of the REAPer is used to excise a botanical in a water relations experiment, the more negative xylem potential commonly observed in water-stressed plants will facilitate greater flux of water into the xylem elements upon excision, compared to non-stressed plants. This will effectively alleviate any internal water deficits for water-stressed plants. Nevertheless, any physiological or biochemical changes that could have occurred within the botanical as a result of a treatment variant, such as water stress prior to the excision, can still be examined. Because all samples across the experimental design can be obtained within a relatively short interval, a "snapshot" of the physiological response is obtained. Consequently, any variance in the response is more closely associated with the treatment variants within the experimental design rather than a result of confounding factors such as changing environmental conditions.

Other than research and development, the REAPer has commercial application in the floral industry. In a global economy where transportation of specialty products, such as tulips (Tulipa gesneriana L.) and longstem roses (Rosa dilecta), occur via special courier services from remote locations (www.aboutflowers.com/floralstats.html), the flower stem may have to be excised from the plant at less than optimal times. This is done so that delivery to a remote destination is profitable. Because the transpiration rate of shoots exceeds water uptake capacity by roots, internal water deficits in plants occur throughout the sunlit period from dawn to midafternoon, thereby causing more negative xylem potentials. Hence, xylem potential is the least negative at predawn and becomes more negative under transpiring conditions until midafternoon. At sunset the xylem potential usually recovers to its predawn level when water supply is adequate, but under water deficits full recovery of xylem potential to predawn levels does not occur completely (Wall, 2001; Wall et al., 2001). Because xylem potential is the least negative at predawn, it is the most optimal time to harvest shoots for market. Harvesting shoots during the sunlit period will cause differences in the distance the resultant emboli will form from the point of excision. Consequently, uncertainty exists about how far up the stem the resultant emboli will form after the initial excision. Even if the second cut is made when the botanical is submerged, it may not resolve the cavitation problem if the section of the botanical removed during the second cut does not contain the preexisting emboli formed during the first cut. If the emboli in the xylem is not removed during the excision process, a reduction in the shelf life of the commercial product is more likely. 
Furthermore, since part of the value of a longstem rose is the length of its stem, any portion of it that is lost due to a second cut decreases the value of the marketable product, as well as increasing the labor cost. Therefore, a common practice in the commercial floral industry is to harvest the daily product demand from floral beds by excising the stem of the flower at predawn when the xylem potential is at its least negative value of the day. This practice ensures that the resultant emboli will be at a minimal distance from the point of the initial excision. The excised stem is then placed in a preservative solution, such as First Flower Food (Spring Sasfenheim, Netherlands), which increases the shelf life of the product by maintaining the turgidity of the plant. A second cut is made while the sample is submerged in solution to offset any cavitation that occurred as a result of an emboli forming in the xylem during the initial excision. Because the distance the resultant emboli formed from the point of the initial excision was kept to a minimum by harvesting at predawn, less stem needs to be removed during the second cut to remove the emboli. The disadvantage of harvesting an estimated amount of product, at the optimal excision time, is that uncertainty exists because the supply of harvested product must match or slightly exceed the daily demand. If an overestimation of demand is made when stems are harvested at predawn, more stems will need to be discarded. Hence, using the REAPer could minimize waste and maximize quality control of the marketable product.

Another advantage of the REAPer is that its reservoir can be filled with floral preservative, nutrients, bacteria stat, growth hormone, or other material to help prolong the shelf life of the botanical. For example, prior to the excision of a botanical a solution of distilled water containing a flower preservative could be used to fill the mariott bottle, and in turn to fill the reservoir. Use of the REAPer, therefore, would not only reduce the number of steps required to harvest the desired product, but because the preservative solution is drawn into the xylem during the excision, it may also increase the shelf life of the product above that currently achieved in industry. In the horticultural industry, an excised botanical can be treated with products such as Hormex Rooting Powder No. 1 (Booker Chemical Co., North Hollywood, Calif.), containing the active ingredient indole-3-butyric acid, prior to being placed in a potting soil medium. If the mariott bottle was filled with a solution containing this type of hormone prior to filling the reservoir of the REAPer, then the solution would enter the xylem elements during the excision. Using the SOP of the REAPer, therefore, could include pretreatment with the hormone, resulting in a decrease in the time required from cutting to viable product.

The potential application of the REAPer is broad-based, encompassing research and development across multiple disciplines, as well as commercial applications-particularly the floral and horticultural industries. Because the REAPer can excise a botanical while preserving the integrity of xylem conductance, it provides a rapid method to collect botanicals in a uniform manner. Consequently, investigations normally performed in situ on intact plants that require too long an interval, can now be conducted on botanicals that have been excised and stored in vivo under exacting steady-state laboratory conditions. Although preliminary results have shown promise, further investigation of the REAPer is warranted to determine its broad-based utility across different species and function types as a SOP in research and development, and as an industrial standard in the commercial floral and horticultural industries. These investigations are presently under way.

\section{Literature Cited}

Bakrim, N., C. Echevarria, C. Cretin, M. ArrioDupont, J.N. Pierre, J. Vidal, R. Chollet, and P. Badal. 1992. Regulatory phosphorylation of Sorghum leaf phosphoenolpyruvate carboxylase identification of the protein-serine kinase and some elements of the signal-transduction cascade. Eur. J. Biochem. 204:821-830.

Barratt, D.H.P., and J.A. Clark. 1992. A stressinduced, developmentally regulated, highly polymorphic protein family in Pisum sativum L. Planta 191:7-17.

Carter, P.J., M.B. Wilkins, H.G. Nimmo, and C.A. Fewson. 1995. Effects of temperature on the productivity of phosphoenolpyruvate carboxylase and on the control of $\mathrm{CO}_{2}$ fixation in Brophyllum fedtschenkoi. Planta 196:375-380.

Davis, D.T. and J.R. Potter. 1983. High $\mathrm{CO}_{2}$ applied to cuttings: Effects on rooting and subsequent growth in ornamental species. HortScience 18(2):194-196.

De la Torres, A., B. Delgado, and C. Lara. 1991. Nitrate-dependent $\mathrm{O}_{2}$ evolution in intact leaves. Plant Physiol. 96:898-901.

Delhon, P., A. Gojon, P. Tillard, and L. Passama. 1996. Diurnal regulation of $\mathrm{NO}_{3}^{-}$uptake in soybean plants III. Implication of the Dijkshoorn-Ben Zioni model in relation with the diurnal changes in $\mathrm{NO}_{3}^{-}$assimilation. J. Expt. Bot. 47(300):885-892.

Housley, T.L., and C.J. Pollock. 1985. Photosynthesis and carbohydrate metabolism in detached leaves of Lolium temulentum L. New Phytol. 99:499-507.

Jia, W., J. Zhang, and D. Zhang. 1996. Metabolism of xylem-delivered ABA in relation to $\mathrm{ABA}$ flux and concentration in leaves of maize and Commelina communis. J. Expt. Bot. 47(301): 1089-1091.

Krapp, A., P. Quick, and M. Stitt. 1991. Ribulose- 1,5-biphosphate carboxylase-oxygenase, other Calvin-cycle enzymes, and chlorophyll decrease when glucose is supplied to mature spinach leaves via the transpiration stream. Planta 186:58-69.

Li, B., X.-Q. Zhang, and R. Chollet. 1996. Phoshoenolpyruvate carboxylase kinase in tobacco leaves is activated by light in a similar but not identical way as in maize. Plant Physiol. 111: 497-505.

Long, S.P., and J-E. Hällgren. 1993. Measurements of $\mathrm{CO}_{2}$ assimilation by plants in the field and the laboratory, p. 129-167. In: D.O. Hall, J.M.O. Scurlock, H.R. Bolhar-Nordenkampf, R.C. Leegood and S.P. Long (eds.). Photosynthesis and production in a changing environment: A field and laboratory manual. Chapman and Hall, London.

McCully, M.E. 1999. Root xylem embolisms and refilling. Relation to water potentials of soil, roots, and leaves, and osmotic potentials of root xylem sap. Plant Physiol. 119:1001-1008.

Pena-Cortes, H., X. Liu, J.S. Serrano, R. Schmid, and L. Willmitzer. 1992. Factors affecting gene expression of patatin and proteinase-inhibitor-II gene families in detached potato leaves: Implications for their co-expression in developing tubers. Planta 186:495-502.

Savage, M.J.,A. Cass, and H.H. Wiebe. 1984. Effect of excision on leaf water potential. J. Expt. Bot. 151:204-208.

Sugiharto, B., J.N. Burnell, and T. Sugiyama. 1992. Cytokinin is required to induce the nitrogen-dependent accumulation of mRNAs for phosphoenolpyruvate carboxylase and carbonic anhydrase in detached maize leaves. Plant Physiol. 100:153-156.

Van Wijk, K.R. and P.R. van Hesselt. 1993. Photoinhibition of photosystem II in vivo preceded by down-regulation through light-induced acidification of the lumen: Consequences for the mechanism of photoinhibition in vivo. Planta 189:359-368.

Wall, G.W., N.R. Adam, T.J. Brooks, B.A. Kimball, P.J. Pinter Jr., R.L. LaMorte, F.J. Adamsen, D.J. Hunsaker, G. Wechsung, F. Wechsung, S. Grossmann-Clarke, S. Leavitt,A.D. Matthias, and A.N Webber. 2000. Acclimation response of spring wheat in a free-air $\mathrm{CO}_{2}$ enrichment (FACE) atmosphere with variable soil nitrogen regimes. 2. Net assimilation and stomatal conductance of leaves. Photo. Res. 66:79-95.

Wall, G.W. 2001. Elevated atmospheric $\mathrm{CO}_{2}$ alleviates drought stress in wheat. Agr., Ecosys. Environ. 87(3):261-271.

Wall, G.W., T.J. Brooks, N.R. Adam, A. Cousins, B.A. Kimball, P.J. Pinter, Jr., R.L. LaMorte, J. Triggs, M.J. Ottman, S.W. Leavitt, A.D. Matthias, D.G. Williams, and A.N. Webber. 2001. Elevated atmospheric $\mathrm{CO}_{2}$ improved Sorghum plant water status by ameliorating the adverse effects of drought. New Phytologist 152:231-248

Zeyen, R.J., W.R. Bushnell, T.L.W. Carver, M.P. Robbins, T.A. Clark, D.A. Boyles, and C.P. Vance. 1995. Inhibiting phenylalanine ammonia lyase and cinnamyl-alcohol dehydrogenase suppresses Mla1 (HR) but not mlo5 (non-HR) barley powdery mildew resistances. Physiol. Mol. Plant. Pathol. 47:119-140. 